\title{
A REGIONAL STUDY OF NET MIGRATION RATES OF COLLEGE STUDENTS
}

\author{
Yu Hsing and Franklin G. Mixon, Jr.
}

\begin{abstract}
In this study, we examine the determinants of college student migration based on a sample of 50 states in 1992. Major findings show that the net migration rate of college students is negatively correlated with per capita personal income, tax burdens, and crime rates, but positively associated with the number of colleges and universities, expenditure per student, educational level of the population, and growth rate of employment. Past migration also significantly affects current migration. The unemployment rate and the wage rate in manufacturing are found to be insignificant.
\end{abstract}

\section{INTRODUCTION}

In recent years extensive research on migration has been prominent in the economics literature. In Greenwood $(1975,1985)$, reviews of migration literature suggest that the migration of college students has received little attention, yet is important for a number of reasons. According to Current Population Reports (P20-473), published by the U.S. Bureau of the Census, the college-age population showed a relatively higher percent of distribution of out-of-state migration than other age groups. Large numbers of out-migrating college students to other states may indicate the underutilization of existing capacity, the loss of revenues to colleges in resident states, poor job opportunities, and lower earnings potential, whereas migration of college students into a state is likely to raise revenues for colleges. According to the National Center for Education Statistics, in 1992, North Carolina, Massachusetts, and Pennsylvania had a net in-migration of 9078 , 8452,6529 students, respectively, whereas New Jersey, Illinois, and Connecticut experienced a net out-migration of $19,820,8,176$, and 4,862 students, respectively. Table 1 details the number of net in-migration and total enrollment for new undergraduate students across states for 1992. In some of the states, such as New York and California, net in-migration was relatively small due to the cancellation of large in-migration and large out-migration.

Because out-of-state students pay a higher tuition than in-state students, and because colleges may need to hire more faculty and increase spending in other

\footnotetext{
*Professor and Head, Department of Economics and Business Research, College of Business, Southeastern Louisiana University, Hammond; and Assistant Professor, Department of Economics and International Business, College of Business Administration, University of Southern Mississippi, Hattiesburg. We are grateful to the editors and two anonymous referees for insightful comments. The usual caveat applies.
} 
TABLE 1

Net Migration and Total Enrollment of New Undergraduate Students by State: 1992

\begin{tabular}{lrrlrr}
\hline \hline & $\begin{array}{c}\text { Net } \\
\text { migration }\end{array}$ & $\begin{array}{c}\text { Total } \\
\text { enrollment }\end{array}$ & & $\begin{array}{c}\text { Net } \\
\text { migration }\end{array}$ & $\begin{array}{c}\text { Total } \\
\text { enrollment }\end{array}$ \\
\hline AL & 5,322 & 42,234 & MT & -223 & 6,413 \\
AK & -994 & 2,480 & NE & -37 & 16,156 \\
AZ & 3,202 & 30,438 & NV & -605 & 4,521 \\
AR & 613 & 18,364 & NH & 1,989 & 11,297 \\
CA & 2,254 & 213,910 & NJ & $-19,820$ & 44,611 \\
& & & & & \\
CO & 3,742 & 34,082 & NM & -315 & 11,419 \\
CT & $-4,862$ & 22,769 & NY & $-3,217$ & 153,852 \\
DE & 1,395 & 7,227 & NC & 9,078 & 55,013 \\
FL & 2,796 & 70,565 & ND & 1,584 & 8,684 \\
GA & 771 & 52,148 & OH & 1,713 & 91,169 \\
& & & & & \\
HI & -199 & 9,445 & OK & 344 & 30,050 \\
ID & 1,621 & 10,960 & OR & 1,380 & 22,733 \\
IL & $-8,176$ & 114,044 & PA & 6,529 & 100,964 \\
IN & 5,388 & 49,304 & RI & 4,767 & 12,813 \\
IA & 4,021 & 36,538 & SC & 1,173 & 20,906 \\
KS & 2,342 & 25,453 & SD & 400 & 6,398 \\
KY & 1,843 & 29,114 & TN & 1,713 & 34,622 \\
LA & 1,634 & 31,810 & TX & 1,038 & 124,246 \\
ME & $-1,294$ & 8,765 & UT & 4,605 & 23,536 \\
MD & $-3,026$ & 33,288 & VT & 1,796 & 6,274 \\
& & & & & \\
MA & 8,452 & 59,460 & VA & 3,806 & 44,683 \\
MI & -999 & 87,772 & WA & 2,348 & 64,913 \\
MN & -618 & 41,718 & WV & 1,938 & 16,941 \\
MS & 1,670 & 24,848 & WI & 1,050 & 46,043 \\
MO & 2,446 & 38,821 & WY & -441 & 3,817 \\
\hline SO & & & & & \\
\hline
\end{tabular}

Source: Digest of Education Statistics, 1993.

areas, losses or gains of revenues are difficult to estimate. However, persistent net out-migration or in-migration suggests financial issues for state governments and colleges.

The migration of college students is a decision which involves both costs and benefits. The costs include higher out-of-state tuition and other expenses, social and psychic costs due to being away from home and friends, and the risk and uncertainty involved in the migration. Potential benefits may include better quality 
of higher education, new opportunities, higher potential earnings, financial aid, etc. College students weigh marginal benefits against marginal costs and make decisions to migrate if the expected value of future earnings of migration is greater than the marginal costs.

Tuckman (1970) pioneered the study of the migration of college students. Based on the data for 49 states in 1963, he found that the out-of-state migration rate has a negative and significant correlation with average tuition for colleges and universities within the state. The coefficient of income was found to be either positive or insignificant depending upon whether voluntary or involuntary outmigration rates are used. Student financial aid was found to be insignificant. The number of public colleges within the state was found to be negative and significant.

Based on a sample of 220 four-year colleges randomly selected from Peterson's Guide to American's Colleges and Universities, Mixon and Hsing (1994a, 1994b) found that out-of-state students are affected by the size of an institution, class size, entrance difficulty scale, the quality of academic programs such as the student/faculty ratio and percent of faculty with terminal degrees, successful athletic programs, and college selectivity. Mixon and Hsing (1994a, pp. 70-71) also find a significant relationship between out-of-state enrollment and an aggregated regressor representing a university's overall performance regarding student satisfaction, financial resources, faculty resources, student selectivity, and academic reputation.

This paper extends the work of Tuckman (1970), Mixon and Hsing (1994a, 1994b) and others to examine the migration of college students, but differs from previous studies of college student migration in several aspects. First, the net migration rate is used as the dependent variable. As Greenwood (1975) suggested, regional studies should provide policy implications and applications. From a policy viewpoint, the net migration rate may help us better understand the complex picture of the bilateral migration of college students. ${ }^{1}$ Past migration is also considered to test the 'beaten-path effect,' which states that current migration is affected by the past migration of relatives and friends. The weighted least squares (WLS) and the OLS methods are both employed in empirical work to compare relative performance. Finally, the 1992 data used in this study are more recent than that of previous studies.

The paper is organized in the following manner. The theoretical framework is described in the second section. Empirical results, including the estimated regression, hypothesis tests, and the interpretations, are presented in the third section. The last section summarizes major findings and discusses implications. 


\section{THE MODEL}

There are many determinants of migration (Greenwood, 1985, pp. 527-534). When microdata are used, individual or household characteristics can be considered and tested. When aggregate cross-sectional or time series data are employed, the number of variables that can be considered is substantially smaller than models that employ microdata. Because this study relies on data for states, variables representing life-cycle considerations and individual characteristics are not considered. We also recognize that by employing macrodata, our model is limited in its ability to analyze spatial dimensions inherent in any migration analysis. Any spatial view of migration can be modeled through parameters that reflect point of origin, destination and distance. To date, actual microdata on this subject do not exist, precluding modeling in this fashion. As suggested above (Mixon and Hsing, 1994a and 1994b) institutional level data do exist. However, as pointed out (Mixon and Hsing, 1994b), modeling with institution data is not measuring college student migration (per se), but the determinants of out-of-state enrollments. At present, the only way to accurately model college student migration is by employing macrodata.

Based on previous studies and migration theory, ${ }^{2}$ the net migration rate of new undergraduate college students can be expressed as:

NET $_{i}=f_{\left(T_{U} T_{i}\right.}$, PCPI $_{i}$, NUM $_{i}, \operatorname{EXP}_{i}$, EDU $_{i}$, GEMP $_{i}$, TAX $_{i}$, CRM $\left._{i}, N T_{i, t-n}\right)$

where

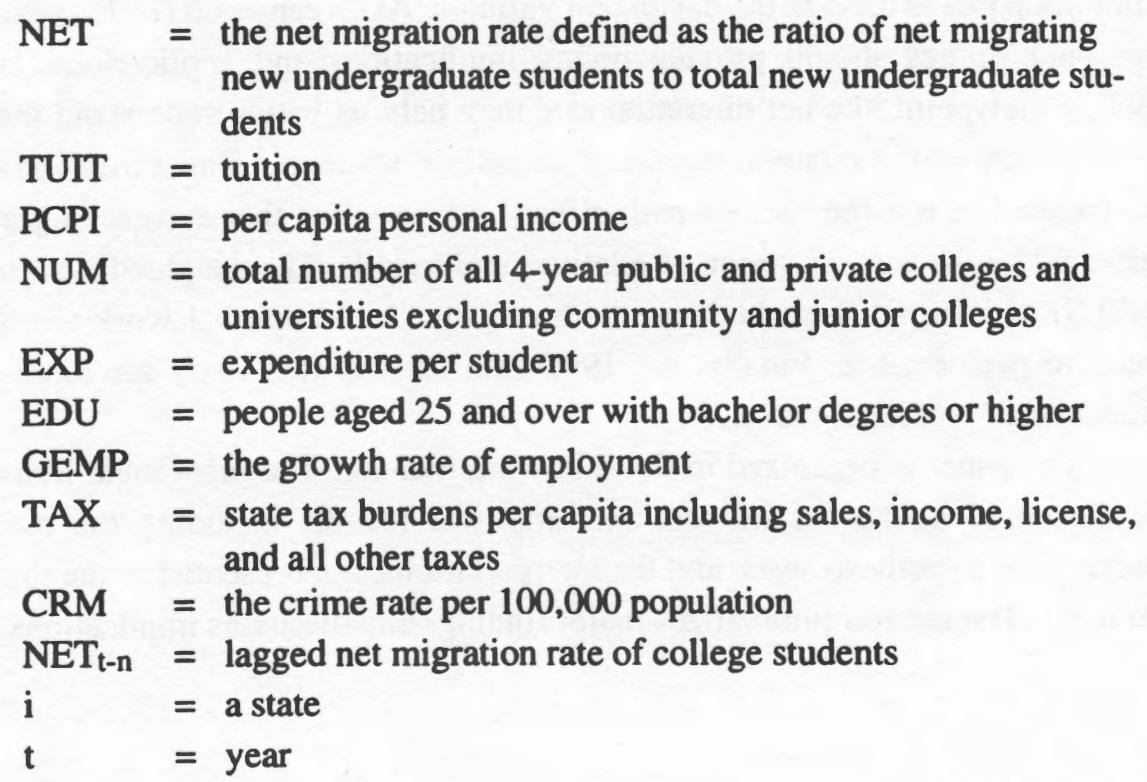


Following Tuckman (1970), tuition, income, and number of colleges are considered in this study. Instead of using financial aid, we choose expenditure per student to represent the overall financial support and the quality of higher education in a state. As pointed out by Tuckman (1970), using financial aid data from sources such as the Digest of Education Statistics creates a measure that fails to separate vested aid (i.e., aid available to the student regardless of college choice) from aid available at certain colleges only. This problem likely confounds the empirical results and leads to an insignificant regressor. Expenditure per student (EXP) represents the support and quality of education (Herzog and Schlottmann, 1986 and 1991). When EXP rises, we expect more in-migration and less outmigration of students.

When tuition is raised, fewer college students are likely to come to a state and some students are expected to migrate to other states to search for a lowercost college education. Thus, the sign of TUIT is expected to be negative. The sign of PCPI may be negative or positive, because higher income may provide more resources (one of the least expensive sources of funding open to students is monetary gifts from parents) and enable students to migrate out of a state, or signal better compensation and encourage in-migration (Greenwood, 1975). The determination of out-of-state or in-state higher education as a normal good is difficult to assess.

When the number of colleges (UNM) increases, students have more choices and a diversified set of college opportunities. This is likely to reduce out-migration and increase in-migration. Educational attainment (EDU) of those 25 or above may affect college migration (Sandell 1977; Schlottmann and Herzog 1981), as higher educational attainment (EDU) may increase out-migration, but it also represents a better quality of the population and work force to attract inmigration of college students. Thus, the net impact of an increase in educational attainment is uncertain. The use of the employment growth rate (GEMP) tests a tenet of human capital theory, because migrants will also attempt to increase their job opportunities and earnings (Muth 1971; Nakosteen and Zimmer, 1980; Molho, 1984; and others). GEMP is expected to be positively related to in-migration, negatively related to out-migration, thus positively related to net migration.

Higher tax burdens (TAX) (Tiebout, 1956; Herzog and Schlottmann, 1986; Cebula, 1990) and crime rates (CRM) (Porell, 1982) may reduce the net migration rate of college students. Tax burdens relate directly to the disposable real return to investments in education, while crime rates can be considered negative consumption benefits (characteristics) associated with college education. In a micro analysis, campus crime rates work well in describing the hazard associated with attending a particular university. ${ }^{3}$ However, we argue that in an aggregate data model, the overall crime rate for a state will likely proxy the costs 
(socioeconomic) of attending universities within that state. These will reduce inmigration and increase out-migration, thus reducing net migration.

The lagged net migration rate of college students is included to indicate that migration involves risk and uncertainty, that it takes time and that it is costly to obtain information from the destination (Molho 1984; Herzog, Hofler, and Schlottmann 1985; Stark and Bloom, 1985; Tabuchi, 1985). College students may make migration decisions based on the past behavior of relatives and friends. The probability of migration is higher if relatives and friends migrated into a state with positive experiences.

The expected impacts of a change in the independent variables on in-migration, out-migration, and net migration are summarized below:

\section{TUIT PCPI NUM EXP EDU GEMP TAX CRM NET t-n}

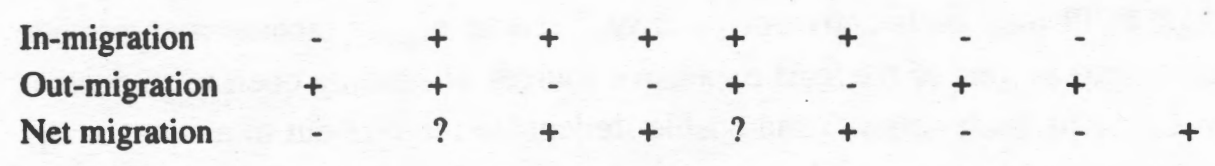

Note that the use of the net migration rate may involve the loss or distortion of valuable information, because any variable in the in-migration and out-migration equations with different signs would have an enlarged effect in the net migration equation, whereas any variable with the same sign would have uncertain or little effect on net migration (Greenwood, 1975, p. 408; Vanderkamp, 1972).

\section{EMPIRICAL RESULTS}

The sample consists of 50 states. The net migration rate is defined as the difference between in-migration and out-migration of new undergraduate students as a percent of enrolled new undergraduate students. Data for NET, TUIT, NUM, and EXP came from the Digest of Education Statistics, National Center for Education Statistics, U.S. Department of Education. ${ }^{4}$ PCPI was taken from the Survey of Current Business, U.S. Department of Commerce. EDU was obtained from the 1990 Census of Population, the U.S. Bureau of the Census. GEMP came from Employment, Hours, and Earnings, U.S. Department of Labor. TAX came from State Government Tax Collections: 1992, U.S. Department of Commerce.

Data for 1992 were collected for NET, TUIT, NUM, EXP, PCPI, GEMP, TAX and CRM. For EDU, only the 1990 Census data are available. 1988 $\left(\mathrm{NET}_{\mathrm{i}, \mathrm{t}-4}\right)$ data are used for the lagged dependent variable, because of lack of data for $1991\left(\mathrm{NET}_{\mathrm{i}, \mathrm{t}-1}\right)$. 
The weighted least squares (WLS) method assuming dependent variable heteroscedasticity is used to correct for any potential problem of variable variances. If heteroscedasticity exists and the OLS is used, the error variances are biased and the hypothesis tests are invalid.

The issue of functional forms may need a brief explanation, as Greenwood (1985) and Goss and Chang (1983) indicate that this is one of the areas deserving more attention in migration research. Because the dependent variable NET has both positive and negative values, we cannot transform the variable based on the Box-Cox model. Thus, the issue of functional forms cannot be formally tested in this study. However, we do compare the explanatory power and other statistical results for the $\log$ and the linear forms. Results show that the $\mathrm{R}^{2}$ of the linear form is only 0.607 and the sign of TUIT, TAX and CRM is incorrect. Thus, the log form yields a better statistical outcome and is chosen.

Empirical results are presented in Table 2. As shown, in the OLS estimation the coefficients of TUIT, PCPI, NUM, TAX, and CRM are insignificant at the $10 \%$ level, and the coefficient of EDU is significant at the 10 percent level only. In the regression estimated with the WLS method, approximately 83 percent of the variation of net migration rates can be explained by the right-hand-side variables. All of the coefficients have the expected signs and are significant at the 1 percent or 5 percent level, except for the tuition variable. The coefficient of TUIT has a correct sign but is insignificant at the 10 percent level, probably because the relatively high correlation coefficient of 0.579 between TUIT and EXP may cause multicollinearity, resulting in larger standard errors and smaller $t$ test statistics. Another possible reason for the insignificant TUIT is that we use instate tuition due to lack of data for out-of-state tuition, whereas out-of-state tuition is considered by migrant students in the first year. ${ }^{5}$ Specifically, an increase in income, tax burdens, or crime rates will reduce net migration rates. Net migration rates will rise with more (and a more diverse set of) colleges, ${ }^{6}$ financial support, educational attainment, and job growth. Past migration is also found to affect current migration. An analysis of empirical work suggests that past migration behavior is the most important independent variable in terms of explanatory power.

Distance, the unemployment rate, the hourly wage rate in manufacturing, and a binary variable representing the Deep South were also tested to take into consideration the actual cost of moving and psychic cost of adjusting to a new environment, the labor market condition and potential earnings. The impact of distance on net migration is likely to be zero if the effects on in-migration and out-migration are symmetric and cancel out. Because of the use of aggregate state data, information for actual distance is not available. In order to take into account the distance factor, the authors constructed a dummy variable for some of the states (HI, AK, WA, ID, MT, ND, MN, and ME), which are either far away from 
TABLE 2

Estimated Regressions of Net Migration Rates of New Undergraduate College Students: 1992

\begin{tabular}{lcc}
\hline \hline Variables & OLS & WLS \\
\hline TUIT $_{i}$ & -0.858 & -0.979 \\
& $(-0.207)$ & $(-1.151)$ \\
PCPI $_{i}$ & -9.937 & $-10.780^{* * *}$ \\
& $(-0.781)$ & $(-3.855)$ \\
NUM $_{i}$ & 0.508 & $0.560^{* *}$ \\
& $(0.399)$ & $(2.247)$ \\
EXP $_{i}$ & $12.336^{* *}$ & $13.000^{* * *}$ \\
& $(1.822)$ & $(6.497)$ \\
EDU $_{i}$ & $9.720^{*}$ & $10.436^{* * *}$ \\
& $(1.346)$ & $(5.464)$ \\
GEMP $_{i}$ & $1.784^{* *}$ & $1.825 * * *$ \\
& $(1.840)$ & $(9.192)$ \\
TAX $_{i}$ & -4.354 & $-4.187 * * *$ \\
& $(-0.789)$ & $(-2.791)$ \\
CRM $_{i}$ & -1.099 & $-1.039 * * *$ \\
& $(-0.579)$ & $(-2.909)$ \\
NET $_{i, t-4}$ & $0.606 * * *$ & $0.612^{* * *}$ \\
& $(10.300)$ & $(16.070)$ \\
INT $^{2}$ & 85.043 & $89.099 * * *$ \\
R $^{2}$ & $(0.762)$ & $(3.221)$ \\
\hline
\end{tabular}

Notes: The dependent variable is the net migration rate of new undergraduate college students. In the WLS estimation, dependent variable heteroscedasticity is assumed.

Figures in parentheses are t-ratios.

$* * *, * *$ or $*$ indicates that the coefficient is significant at the $1 \%, 5 \%$ or $10 \%$ level.

the continent or are regarded as relatively remote areas. The coefficient of the dummy variable is estimated to be -1.633 and significant at the 2.5 percent level, suggesting that the impact on in-migration outweighs that on out-migration.

The unemployment rate was considered by many scholars in migration research, including Salvatore (1977), Ledent (1983), Molho (1984), and others. In this study, results show that the coefficient of the unemployment rate is positive and significant, which is inconsistent with Greenwood (1985, p. 532). Thus, the growth rate of employment is assumed to be a better indicator of job opportunities. Krumm (1983) and others found the wage rate to be significant, insignificant, or not to exhibit any pattern. The coefficient of the hourly wage rate in manufacturing is negative and significant, and thus counter to expectations. One possible reason is that personal income per capita and the hourly wage rate in 
manufacturing are highly correlated, resulting in a change of the sign. Finally, Jones and Jackson (1990), in a study of labor market earnings and college grades, provide evidence that post-graduation residence in the Southern state containing the state university is negatively related to earnings five years after graduation. Based on this idea, we also include a binary variable equal to one for Deep South states, and zero otherwise. The expected sign of this variable was negative; however, the regressor produced insignificant results.

\section{SUMMARY AND CONCLUSIONS}

In this study, we have examined the determinants of net migration rates of college students based on the latest data in 1992 . The major findings can be summarized as follows. The OLS method yields poor results, whereas the WLS method exhibits better statistical outcomes. Increases in income, tax burdens, and crime rates reduce net migration rates, whereas more colleges, greater expenditures per student, higher educational attainment, higher growth of employment, and greater past net migration rates are expected to increase net migration rates. Therefore, human capital theory is confirmed due to the significance of the coefficients for expenditure per student and growth of employment. Meanwhile, we also find that past migration affects current migration due to the well known 'beaten path effect' in the migration literature. Other potential variables, such as the unemployment rate and the hourly wage rate in manufacturing, are considered, but their signs are found to be inconsistent with migration theory.

There are several implications of this study. A state is expected to lose college students if it raises taxes or has a high crime rate. More branch campuses and state universities/colleges may reduce the out-migration of college students. The quality of education needs to be emphasized and greater financial support for colleges and universities is likely to augment net inmigration of college students. In addition, job opportunities need to be created in order to increase net migration of college students.

There are some limitations of this study. Aggregated data for states may wash out valuable information for individuals and households (Navratil and Doyle, 1977). Cross-sectional data were collected in 1992, a year in which some states were subject to recessions or adjustments in particular industries and labor markets. In this regard, Kroncke and Ressler (1993) point out that recessionary periods tend to increase college enrollments. In addition, because the sample uses state data, many individual characteristics such as age, sex, employment, marital status, preferences, and others factors are not available. Finally, environmental concerns have not been considered for the same reason. 
There may be areas for future research. Disaggregated data may be obtained to examine migration decisions of college students at the individual level. Surveys may be conducted to determine how past migration would affect current migration. If data are available, life-cycle factors and quality-of-life variables can be considered.

\section{ENDNOTES}

1. It is understandable that due to lack of data, many regional studies examined only out-migration or in-migration, but not net migration. In this study, net migration is considered because data are available to us. The use of net migration avoids a potential econometric problem of the correlation of error terms in the in-migration and out-migration regressions when both are estimated at the same time. Meanwhile, the problem of the lack of data for distance can be avoided because the net impact of distance is likely to cancel out if effects on inand out-migration are symmetric.

2. In this paper, the labor migration model is applied to the study of college student migration. According to the Digest of Education Statistics, 43.7 percent of college students in 1992 maintained part-time status partly because of employment-related reasons. Based on the College of Enrollment of 1993 High School Graduates published by the U.S. Department of Labor, 1993 high school graduates enrolled in college as of October 1993 had a labor force participation rate of 46.3 percent and an unemployment rate of 14.3 percent. Thus, employment growth, per capita income, or tax rates are important factors in the migration decision of college students, because they affect job opportunities, the availability of financial assistance, and disposable income.

3. For example, the crime incident that occurred at the University of Florida in Gainesville a few years ago is regarded as a major factor in many students' decisions to either transfer out of the school or not to attend in the first place.

4. The migration data came from the "Residence of First-Time Students" obtained from the Integrated Postsecondary Education Data System. It surveys all postsecondary institutions, including colleges, universities, and vocational and technical institutions beyond the high school level. The higher education portion is a census of accredited two- and four-year colleges, while data from the vocational and technical institutions are collected through a sample survey. U.S. Service Schools are included in state totals, but students from foreign countries and outlying areas are excluded.

5. The ratio of out-of-state tuition to in-state tuition may be considered to measure relative cost. However, due to lack of reliable and consistent data for out- 
of-state tuition across states, we are unable to estimate the parameter for the proposed new variable.

6. Based on a referee's suggestion, another variable which may serve as a measure of supply is the ratio of enrolled new freshmen to high school graduates. Alternative model estimates indicate that the coefficient on this variable is $\mathbf{0 . 2 7 5}$ (significant at the 1 percent level).

\section{REFERENCES}

Becker, Gary S. "Investment in Human Capital: A Theoretical Analysis." Journal of Political Economy 70 (1962): 9-49. Supplement, Part 2. . Human Capital. New York: Columbia University Press, 1975.

Cebula, Richard J. "A Brief Note on the Tiebout Hypothesis and State Income Tax Policies." Public Choice 67 (1990): 87-89.

Goss, Ernest, and Hui S. Chang. "Changes in Elasticities of Interstate Migration: Implication of Alternative Functional Forms." Journal of Regional Science 23 (1983): 223-32.

Greenwood, Michael J. "Research on Internal Migration in the United States: A Survey." Journal of Economic Literature 13 (1975): 397-433.

Greenwood, Michael J., and Gary L. Hunt. "Migration and Interregional Employment Redistribution in the United States." American Economic Review 74 (1984): 957-69.

"Human Migration: Theory, Models, and Empirical Studies." Journal of Regional Science 25 (1985): 521-44.

Greenwood, Michael J., Gary L. Hunt, Dan S. Rickman, and George I. Treyz. "Migration, Regional Equilibrium, and the Estimation of Compensating Differentials." American Economic Review 81 (1991): 1382-90.

Herzog, Henry W., Jr., and Alan M. Schlottmann. "Moving Back vs. Moving On: The Concept of Home in the Decision to Remigrate." Journal of Regional Science 22 (1982): 73-82.

."Labor Force Mobility in the United States: Migration, Unemployment, and Remigration." International Regional Science Review 9 (1984): 43-58.

. "High-Technology Jobs and Worker Mobility." Journal of Regional Science 26 (1986): 445-59.

. "Metropolitan Dimension of High-Technology Location in the U.S.: Worker Mobility and Residence Choice." (Edited by Herzog, H. W., Jr., and A. M. Schlottmann) Industry Location and Public Policy, Knoxville: The University of Tennessee Press, 1991, 169-189. 
Herzog, Henry W., Jr., Richard A. Hofler, and Alan M. Schlottmann. "Life on the

Frontier: Migrant Information, Earnings, and Past Mobility." Review of Economics and Statistics 67 (1985): 373-82.

Jones, Ethel B., and John D. Jackson. "College Grades and Labor Market Rewards." Journal of Human Resources 25 (1990): 253-66.

Kroncke, Charles O., Jr., and Rand W. Ressler. "The Alchian-Allen Effect in Higher Education: Public versus Private Enrollment." Economics of Education Review 12 (1993): 345-49.

Krumm, Ronald J. "Regional Labor Markets and the Household Migration Decision." Journal of Regional Science 23 (1983): 361-76.

Ledent, Jacques. "Demoeconomic Modeling of Interprovincial Migration in Canada: The Longitudinal Case." Paper presented at the 23rd European Congress of the Regional Science Association, France, August 30-September 2, 1983.

Mixon, Franklin G., Jr., and Yu Hsing. " College Student Migration and Human Capital Theory: A Research Note." Education Economics 2 (1994a): 65-73. . "The Determinants of Out-of-State Enrollments in Higher Education: A Tobit Analysis." Economics of Education Review 13 (1994b): 329-35.

Molho, Ian. "A Dynamic Model of Interregional Migration Flows in Great Britain." Journal of Regional Science 24 (1984): 317-37.

Muth, Richard F. "Migration: Chicken or Egg." Southern Economic Journal 37 (1971): 295-306.

Nakosteen, Robert A., and Michael Zimmer. "Migration and Income: The Question of Self-Selection." Southern Economic Journal 46 (1980): 840-51.

Navratil, Frank J., and James J. Doyle. "The Socioeconomic Determinants of Migration and the Level of Aggregation." Southern Economic Journal 43 (1977): $1547-59$.

Porell, Frank W. "Intermetropolitan Migration and Quality of Life." Journal of Regional Science 22 (1982): 137-58.

Salvatore, Dominick. "An Econometric Analysis of Internal Migration in Italy." Journal of Regional Science 17 (1977): 395-408.

Sandell, Steven H. "Women and the Economics of Family Migration." Review of Economics and Statistics 59 (1977): 406-14.

Schlottmann, Alan M., and Henry W. Herzog, Jr. "Employment Status and the Decision to Migrate." Review of Economics and Statistics 63 (1981): 590-98.

Stark, Oded, and David E. Bloom. "The New Economics of Labor Migration." American Economic Review 75 (1985): 173-78.

Tabuchi, Takatoshi. "Time-Series Modeling of Gross Migration and Dynamic Equilibrium." Journal of Regional Science 25 (1985): 65-83. 
Tiebout, Charles M. "A Pure Theory of Local Expenditures." Journal of Political Economy 64 (1956): 416-24.

Tuckman, Howard P. "Determinants of College Student Migration." Southern Economic Journal 37 (1970): 184-89.

Vanderkamp, J. "Return Migration: Its Significance and Behavior." Western Economic Journal 10 (1972): 460-65. 
